\title{
The Radboud Dysarthria Assessment: Development and Clinimetric Evaluation
}

\author{
Simone Knuijt ${ }^{\mathrm{a}} \quad$ Johanna G. Kalf ${ }^{\mathrm{a}}$ Baziel G.M. van Engelen ${ }^{\mathrm{b}}$ \\ Bert J.M. de Swart ${ }^{\mathrm{a}, \mathrm{c}}$ Alexander C.H. Geurts ${ }^{\mathrm{a}}$ \\ ${ }^{a}$ Department of Rehabilitation, Donders Institute for Brain, Cognition and Behaviour, Radboud University Medical \\ Center, Nijmegen, The Netherlands; ${ }^{b}$ Department of Neurology, Donders Institute for Brain, Cognition and \\ Behaviour, Radboud University Medical Center, Nijmegen, The Netherlands; ' $\mathrm{HAN}$ University of Applied Sciences, \\ Institute of Health Studies, Nijmegen, The Netherlands
}

\section{Keywords}

Dysarthria · Assessment · Validation

\begin{abstract}
Objective: In the absence of an adequate dysarthria assessment in the Netherlands, we developed the Radboud Dysarthria Assessment (RDA). This article describes its development and clinimetric evaluation. Patients and Methods: Forty-three patients were assessed with the RDA. The recording forms were subjected to exploratory factor analysis and estimation of internal consistency. The self-evaluation questionnaire was tested for internal consistency and the severity scale for intra- and inter-rater reliability. Construct validity of the severity scale and questionnaire was determined by relating them to the Speech Handicap Index (SHI), Dutch sentence intelligibility assessment (NSVO-Z), and category fluency task. Results: Exploratory factor analysis extracted 4 factors (articulation, resonance, phonation, respiration/ prosody) yielding an explained variance of $70.3 \%$. Each factor showed good internal consistency (Cronbach's a: 0.890.91). The self-evaluation questionnaire showed excellent internal consistency (Cronbach's a: 0.90). Intra-class correlation coefficients of the severity scale $(0.85-0.86)$ showed good reliability. The severity scores and self-evaluation
\end{abstract}

questionnaire correlated substantially to strongly with the SHI $\left(r_{\mathrm{s}}=0.40\right.$ and 0.80$)$ and substantially with the NSVO-Z $\left(r_{\mathrm{s}}=-0.65\right.$ and -0.52$)$. Conclusions: The RDA is a valid and reliable tool, but further investigation is needed to demonstrate whether this instrument can successfully support speech-language therapists in correctly diagnosing the type of dysarthria.

(c) 2018 The Author(s)

Published by S. Karger AG, Basel

\section{Introduction}

Dysarthria is a common feature of both central and peripheral neurological diseases, including stroke, brain trauma, neurodegenerative, and neuromuscular disorders. Many speech-language therapists (SLTs), especially those working in acute care, nursing homes, and rehabilitation centres, are regularly confronted with patients who are speaking effortfully, who are poorly intelligible, or who sound abnormal. In these patients, it is important to identify whether the speech disorder can indeed be classified as dysarthria and, if so, what the type and severity of the dysarthria is. This involves insight into the neurological abnormalities regarding the 5 aspects of speech production, i.e. articulation, resonance, phonation, respi-

\section{KARGER}

E-Mail karger@karger.com www.karger.com/fpl
(C) 2018 The Author(s) Published by S. Karger AG, Basel

Karge

Open access

This article is licensed under the Creative Commons AttributionNonCommercial-NoDerivatives 4.0 International License (CC BYNC-ND) (http://www.karger.com/Services/OpenAccessLicense). Usage and distribution for commercial purposes as well as any distribution of modified material requires written permission.
Simone Knuijt, MA

Department of Rehabilitation, Donders Institute for Brain, Cognition and Behaviour Radboud University Medical Centre

PO Box 9101, internal code 898, NL-6500 HB Nijmegen (The Netherlands)

E-Mail simone.knuijt@ radboudumc.nl 
ration, and prosody [1] through proper assessment. In addition, diagnosing the type of dysarthria may support the medical diagnosis because a speech disorder often reflects the localization of neurological dysfunction $[2,3]$. Lastly, a reliable judgment of the severity of dysarthria is needed for adequate monitoring and treatment evaluation.

Unlike aphasia tests, the clinical assessment of dysarthria is typically based on subjective judgments that are often less reliable than objective judgments. The subjective judgment of dysarthric speech is complex and notoriously difficult, because the 5 aspects of speech production interact with each other (e.g., the breathing pattern influences the vocal quality) [2]. On top of that, speech can be influenced by other factors, like cognition, behaviour, dentition, and emotion $[4,5]$. Based on our experience of providing postgraduate dysarthria courses for more than 10 years, we felt that many discussions about treatment are based on inadequate assessment of the dysarthria, resulting in misinterpretation of the dysarthric speech characteristics. We also learned that most SLTs use their own speech tasks and checklists to assess dysarthria. Hence, we felt there was a need for a proper and validated dysarthria assessment, which should be supported by video examples to facilitate the interpretation of the various speech characteristics.

As far as we could find in the international literature, the only published standardised diagnostic instrument for dysarthria in adults is the Frenchay Dysarthria Assessment (FDA-2) [6]. The FDA-1 was translated and made available in the Netherlands between 1996 and 2010 [7], but we learned from our courses and our nationwide contacts that it never became widely used. When the Dutch version of the FDA-1 was no longer for purchase, we decided to improve and validate the Radboud Dysarthria Assessment (RDA) for adult patients that we made available online in 2007 [8] and that we promoted during our postgraduate dysarthria courses. The original RDA was developed at the department of Rehabilitation of the Radboud University Medical Centre, based on the international literature and our clinical practice. It consisted of 2 components: a qualitative recording form and a severity scale, accompanied by a short manual with instructions how to perform and interpret the speech tasks (spontaneous speech, text reading, maximum repetition rate, maximum phonation time, maximum phonation volume [MPV], and fundamental frequency range [FFR]). Since its release in 2007, many SLTs in the Netherlands and Flanders have downloaded this freely available assessment.
We did not translate or promote the FDA-2 for two reasons. First, the FDA-2 combines observation of oral structures and non-verbal oral functions, assessment of speech characteristics, and measurement of intelligibility. Because SLTs in the Netherlands have an orofacial examination at their disposal [9] as well as validated Dutch intelligibility tests on word and sentence levels [10,11], there was no need for an instrument combining all these domains. Second, because the FDA-2 combines several domains, the assessment of speech characteristics is less extensive than we think is needed for a clinician to adequately assess dysarthria. Third, in the FDA-2, the dysarthria types are less specific than clinically required. For instance, hypokinetic and hyperkinetic dysarthrias are both categorised under "extrapyramidal dysarthria," whereas these are clearly two distinctive disorders. Moreover, in the FDA-2, "mixed dysarthria" is applied as a general term, although mixed flaccid/spastic dysarthria as in amyotrophic lateral sclerosis is clearly different from (and requires other a different therapeutic approach than) for example mixed hypokinetic/ataxic dysarthria as in multiple system atrophy.

Our 4-step approach to improve and validate the RDA was to: (1) seek national consensus for the tasks and the qualitative recording form, (2) add a self-evaluation questionnaire, (3) critically evaluate the clinimetric properties of the qualitative recording form, severity scale, and self-evaluation questionnaire, and (4) add training videos of all types and severities of dysarthria including detailed interpretation of the assessment for self-training purposes.

This paper aims to describe the improvement of the original RDA for adult patients (steps 1 and 2) and to report the dimensionality of the qualitative recording form (i.e., whether it is consistent with the 5 aspects of speech production), the internal consistency within each dimension and of the self-evaluation questionnaire, the construct validity of the severity scale and of the self-evaluation questionnaire, and the intra- and inter-rater reliability of the severity scale (step 3). The study that focused on the construction and usefulness of training videos (step 4) to improve the assessment of the type of dysarthria will be published in a separate paper.

\section{Methods}

Approval was obtained from the Medical Ethics Committee of the Radboud University Medical Centre, and all patients signed an informed consent form. 


\section{Improvement of the Original RDA (Steps 1 and 2)}

The process of improving the original RDA was led by an expert group of 7 SLTs working in 4 different hospitals in the Netherlands, 4 of them with more than 30 years of experience in motor speech disorders. The qualitative recording form of the freely available and unvalidated original RDA was thoroughly scrutinised by the expert group based on their experience of using it for 2 years. A major adaptation was to structure the form according to the 5 aspects of speech production and to add information about posture and other speech-related aspects like dentition. Besides, speech characteristics were described more consistently regarding problems in strength, speed, range, tone, and precision of movements. Face validity of the recording form was established as follows. All items were described in detail in the test manual. The members of the expert group tested the recording form in clinical practice, and their comments were collected and discussed until consensus about the recording form was reached. To create even broader support, a Delphi method was used to ask for comments and feedback on the recording form and test manual from SLTs in the Netherlands and Belgium. 177 SLTs were contacted, and $49(27.7 \%)$ agreed to participate. These 49 colleagues worked in different settings (either in an [academic] hospital, rehabilitation centre, nursing home, or private practice), and $58 \%$ of the respondents had more than 10 years of experience with neurological patients. Everyone readily agreed on the speech tasks, but much more time than we anticipated was needed to reach consensus on the terminology in Dutch. We named speech characteristics based on how they were referred to in the international literature $[3,6]$, but we noticed that many SLTs used their own terminology. After discussing all comments in the expert group and defining all terms used, the second versions of the recording form and test manual were constructed. In this process, we also used the feedback obtained after presentations of preliminary versions at international congresses $[12,13]$. Lastly, 3 independent experienced SLTs with a special interest in motor speech disorders thoroughly reviewed the second versions of the test manual and recording form. Based on their feedback, the final version of the RDA was constructed.

The RDA focuses on dysarthria, i.e. on the process of execution of speech. The aims of the RDA are to recognise the speech characteristics that lead to a particular type of (or mixed) dysarthria and to assess the severity of dysarthria. This requires the use of relevant speech tasks, of which spontaneous speech and reading are most functional and representative of daily life. There is a lively discussion about including maximum performance (speechlike) tasks in dysarthria assessment [14]. According to some authors, speech and speech-like tasks are controlled by separate motor control systems $[15,16]$, whereas others believe that motor control of speech and speech-like tasks overlap or are, at least clinically, indistinguishable $[14,17]$. We decided to include maximum performance tasks primarily to facilitate the interpretation of specific characteristics observed in spontaneous speech and reading, such as signs of hypotonia, hypertonia, hypokinesia, hyperkinesia, and ataxia. Indeed, patients need to be challenged to examine the upper limits of especially phonation and articulation [18] to observe their voice and speech capacities without compensations. This is because compensatory strategies are harder to use in maximum performance tasks, thereby uncovering the true nature of the motor disorder. In addition, some types of dysarthria are characterised by a specific pattern in maximum performance tasks. For example, oral dysdiadochokinesis is a feature of ataxic dysarthria $[3,19]$, which manifests itself or becomes more prominent during a maximum repetition task. Another argument in favour of including speech-like tasks is that maximum performance tasks are effort based and can help to identify therapeutic options. For instance, the often normal MPV in hypokinetic dysarthria reveals the voice capacity that is needed for successful training. Therefore, the following tasks were included in the RDA.

Spontaneous Speech by a Semi-Structured Interview. Spontaneous speech is the task most representative of speaking in daily life and was, therefore, selected as the starting point of the assessment of speech characteristics.

Text Reading. When reading out loud, prosodic features like speaking rate and intonation become evident. Besides, fatigue can be provoked when the text is long enough, because there are no interruptions. A fictional reading text ("Niets") [20], already used by many Dutch SLTs, was added after being adapted for acoustic measurements. In the Netherlands, clinicians generally do not use acoustic measurements, but with this adaptation the text was made suitable for a more profound clinical examination as well as for research purposes. We paid particular attention to the correct position of plosives and vowels within words (in stressed or nonstressed syllables) and within sentences, taking into account the normal phonological processes $[21,22]$. Based on these criteria, sentences were rewritten and the final text now consists of 520 words.

Maximum Repetition Rate (Syllables/s). Maximum repetition rate of $/ \mathrm{pa} /, / \mathrm{ta} /, / \mathrm{ka} /$, and $/$ pataka/ was included to assess the upper limits of the articulatory system.

Maximum Phonation Time (s). Maximum phonation time or sustained phonation on /a:/ was included to specifically assess the phonatory-respiratory systems. To distinguish the phonatory from the respiratory aspects of speech production, the sustained productions of $/ \mathrm{s} /$ and $/ \mathrm{z} / \mathrm{can}$ be compared, and the $\mathrm{s} / \mathrm{z}$ ratio can be calculated, with a ratio of $>1.4$ indicating phonatory problems [23]. In the case of respiratory problems, both sustained /s/ and / z/ will be shorter than normal.

Maximum Phonation Volume (dB). MPV was included to examine the dynamic range by asking the patient to produce "Hallo!" (Hello!) and "Kom hier!" (Come here!) as loud as possible. A decline in dynamic range may not be detected in spontaneous speech, because in normal conversation only a small part of the full range is used. Besides, if a loud voice is possible during MPV in a patient with hypokinetic dysarthria, it makes weakness unlikely and shows spare capacity that can be utilised for therapy.

Fundamental Frequency Range (Semitones). FFR was included to examine the melodic range by asking patients to produce an /a:/ from the lowest possible to the highest possible pitch and vice versa. Like in MPV testing, a decline in the FFR may not be detected in spontaneous speech when only a small part of the range is used.

All maximum performance tasks are performed 3 times, and the best performance is rated.

In parallel with the improvement of the RDA, we collected maximum performance reference values of 224 men and women [24] to be able to compare the performance of each patient with the normal population. However, when clinicians do not assess the maximum performance tasks instrumentally (e.g., with PRAAT), they can score the performance of the patient subjectively on a 4 -point Likert scale ranging from " $0=$ normal” to " $3=$ severe problems/impossible.” All other speech characteristics are rated on the 
recording form with this 4-point scale as well. When scoring $\geq 1$, a qualitative judgement has to be given, which is printed on the qualitative recording form. The recording form is shown in Appendix 1. It includes all relevant items to assess the 5 aspects of speech production. We translated the form from Dutch into English only for the purpose of this article and would like to emphasise that the wording is merely indicative of the Dutch original. In the Dutch manual of the RDA, all terms are explained in detail.

For the judgement of the severity of dysarthria, we included a 6-point scale inspired by the Therapy Outcome Measures [25] ranging from " $0=$ normal" to " $5=$ most severe." The scores $1-5$ were defined by applying the terminology of the qualitative recording form (Appendix 1). This severity score is an overall score that reflects the interpretation of the performance on all different tasks and it is given after completion of the full assessment. When a patient scores mostly 0 or 1 on the qualitative recording form, the overall severity is considered to be mild. The overall severity score reflects the most severely affected aspect of speech production, so when, for example, the articulation is more severely affected than the phonation, the severity score will reflect the severity of the articulation.

Lastly, we included a short self-evaluation questionnaire to quantify the patient's speech complaints and experienced consequences in daily functioning, but also as a clinical guidance for the history taking. We adjusted the Radboud Oral Motor inventory for Parkinson's disease (ROMP-speech) [26] by replacing 2 items that were specific for hypokinetic dysarthria (vocal quality and starting problems) by items for all types of dysarthria (ability to speak for a longer period and ability to raise the voice). The self-evaluation questionnaire consists of 7 questions with a 5-point response scale that cover the "function," "activity," and "participation" domains of the International Classification of Functioning, Disability and Health (ICF) [27], yielding a total score from 7 (no complaints) to 35 (most severe complaints).

Clinimetric Evaluation of the RDA (Step 3)

Table 1 provides an overview of the clinimetric evaluations that we used to validate the different parts of the RDA.

\section{Patients}

Forty-three adult patients with dysarthria were recruited from the 4 hospitals to which the members of the expert group were affiliated. No specific inclusion or exclusion criteria were applied, because the aim was to collect examples of all dysarthria types and severities.

\section{Raters}

Usually, the expert SLT who included the patient also made the video recordings of the dysarthria assessment, with a high definition camera and a separate microphone. After completion of all videos, the expert group discussed the type and severity of the dysarthria of each patient until full agreement was reached, while they were kept unaware for the clinical information (medical diagnosis, etc.).

Forty-six SLTs were approached by e-mail to ask for participation. This e-mail was sent to a study group of SLTs working in hospitals across the Netherlands and to a group of SLTs working with neurological patients in the region of Nijmegen. Twenty-two of them (48\%), with on average 11 years of experience with dysarthria (range 2-24 years), agreed to participate.
Table 1. Overview of the clinimetric evaluations

\begin{tabular}{ll}
\hline Clinimetric characteristic & $\begin{array}{l}\text { Based on judgement or } \\
\text { scores by: }\end{array}$ \\
\hline $\begin{array}{l}\text { Qualitative recording form } \\
\text { Face validity }\end{array}$ & $\begin{array}{l}\text { Expert group } \\
\text { Dimensionality } \\
\text { Internal consistency }\end{array}$ \\
$\begin{array}{l}\text { Expert group } \\
\text { Expert group }\end{array}$ \\
$\begin{array}{l}\text { Construct validity } \\
\text { Reliability }\end{array}$ & $\begin{array}{l}\text { Expert group } \\
\text { Celf-evaluation questionnaire }\end{array}$ \\
$\begin{array}{l}\text { Construct validity } \\
\text { Internal consistency }\end{array}$ & $\begin{array}{l}\text { Patients } \\
\text { Patients }\end{array}$ \\
\hline \multicolumn{2}{l}{ SLTs, speech-language therapists. } \\
\end{tabular}

\section{Construct Validity}

To evaluate the construct validity of the severity scale (severity score given by the expert group) and the self-evaluation questionnaire, the scores were compared with (a) the Speech Handicap Index (SHI) [28], (b) the Dutch sentence intelligibility assessment (NSVO-Z) [11], and (c) a category fluency task [29]. The SHI and NVSO-Z were used to test convergent validity, whereas the category fluency task was used to test divergent validity as it assesses linguistic skills rather than speech. The NSVO-Z and the category fluency task were performed and videotaped after the assessment with the RDA by the expert SLT. Patients completed the self-evaluation questionnaire at home, maximally 1 week before the assessment. The expert SLT who performed the assessment of the RDA, NSVO-Z, and category fluency task was unaware of the patient's scores on the SHI and the self-evaluation questionnaire.

The SHI is a validated self-reported Dutch questionnaire for dysarthric patients containing 15 questions about dysarthria in the physical, functional, and emotional domains. Patients answer the SHI questions on a 5-point-scale from "never" to "always" (0-4) generating a total score ranging from 0 to 60 . The NSVO-Z contains 1,200 semantically unpredictable sentences. For each patient, 18 sentences are randomly generated, which have to be read out loud. A member of the expert group, who was not responsible for videotaping the patient, transcribed all sentences spoken by the patient before discussing the type and severity of the dysarthria. The first author (S.K.) compared the transcription to the original sentences, resulting in a percentage of intelligibility for each patient. The category fluency task requires naming as many animals as possible in $1 \mathrm{~min}$. The total number of animals is converted into a $z$-score dependent on age and level of education [29]. When a slow speaking rate is responsible for a limited amount of animals, correction is allowed. We hypothesised substantial to strong correlations $\left(r_{\mathrm{s}}>0.40\right)$ [30] of the severity scale and the self-evaluation questionnaire with the SHI and the NSVO-Z, whereas weak correlations $\left(r_{\mathrm{s}}<0.40\right)$ were expected with the category fluency task.

\section{Reliability}

Twenty-two SLTs agreed to score a set of videos at two separate times. Three SLTs scored 10 selected videos twice, with a 2 -week interval, to assess the intra-rater reliability of the severity scale. The 
Table 2. Overview of the type and severity of the dysarthria and the medical diagnosis of the 43 patients

\begin{tabular}{|c|c|c|c|c|c|c|}
\hline 2 & $\begin{array}{l}\text { Stroke }(n=2) \\
\text { FSHD }(n=1) \\
\operatorname{MD}(n=1)\end{array}$ & $\mathrm{CP}(n=1)$ & $\begin{array}{l}\text { Cerebellar ataxia }(n=2) \\
\text { MS }(n=1) \\
\text { MSA }(n=1)\end{array}$ & & $\begin{array}{l}\text { Dystonia }(n=1) \\
\text { Huntington's disease }(n=1)\end{array}$ & \\
\hline 4 & Stroke $(n=2)$ & $\mathrm{CP}(n=1)$ & & $\begin{array}{l}\operatorname{PD}(n=2) \\
\operatorname{MSA}(n=1) \\
\operatorname{MSA}(n=1)\end{array}$ & $\begin{array}{l}\text { Dystonia }(n=1) \\
\text { Huntington's disease }(n=1)\end{array}$ & $\begin{array}{l}\text { Stroke }(n=2) \\
\text { PLS }(n=1) \\
\text { TBI }(n=1) \\
\operatorname{PSP}(n=1)\end{array}$ \\
\hline
\end{tabular}

1, minimal dysarthria; 2, mild dysarthria; 3, mild/severe dysarthria; 4, severe dysarthria; 5, very severe dysarthria; TBI, traumatic brain injury; CP, cerebral palsy; PD, Parkinson's disease; PLS, primary lateral sclerosis; MSA, multiple system atrophy; PSP, progressive supranuclear palsy; MS, multiple sclerosis; FSHD, facioscapulohumeral muscular dystrophy; MD, myotonic dystrophy; MG, myasthenia gravis.

videos included minimally 1 example of each severity level and the SLTs scored the videos independently using a secured online connection. The other 19 SLTs scored 10 selected videos before and after an online video-training. Inter-rater reliability of the severity scale was determined by comparing their scores of the second assessment (after the online training).

\section{Dimensionality and Internal Consistency}

The qualitative recording forms filled in by the expert group during the consensus process were used to assess the dimensionality and internal consistency of the recording form. The self-evaluation questionnaires completed by the patients were used to calculate the internal consistency of the questionnaire.

\section{Statistics}

An exploratory factor analysis was performed to evaluate whether the items on the qualitative recording form loaded on the factors that corresponded with the a priori defined 5 aspects of speech production (articulation, resonance, phonation, respiration, and prosody). Principal axis factoring was used as the extraction method together with varimax rotation. Extraction of the factors was based on the Kaiser's criterion for eigenvalues being equal to or greater than 1.0. Cronbach's a was used to calculate the internal consistency of each factor found and to test the internal consistency of the self-evaluation questionnaire.

Construct validity was determined by calculating Spearman's correlation coefficients of the severity scale and the self-evaluation questionnaire with the SHI, NSVO-Z, and the category fluency task. We a priori considered (absolute) correlation coefficients $<0.40$ as "weak," $0.40-0.70$ as "substantial," and $>0.70$ as "strong" [30].

Radboud Dysarthria Assessment
The intra-class correlation coefficient (ICC) for consistency (two-way random) was used to calculate the intra- and inter-rater reliability of the severity scale. A value of 0.70 was considered as a minimum standard for reliability [31]. Calculations were performed with IBM SPSS Statistics 20 for Windows (IBM Corp., Armonk, NY, USA) and SAS 9.2 for Windows (SAS Institute, Cary, NC, USA).

\section{Results}

We included 18 women and 25 men with a mean age of 61 years (range 14-79 years). Table 2 provides an overview of the type and severity of dysarthria in these 43 patients (including their medical diagnosis). Their mean SHI score was 24 (range 6-49), the mean NSVO-Z score $86 \%$ (range 33.9-100), and the mean ROMP score 18 (range 9-35).

\section{Qualitative Recording Form}

The exploratory factor analysis extracted 4 dimensions yielding an explained variance of $70.3 \%$ with all items loading on 4 components. Those components could be identified as: phonation (1), articulation (2), respiration/ prosody (3), and resonance (4) (Table 3). Cronbach's a was between 0.89 and 0.91 for the individual factors, indicating good internal consistency within each dimension. 


\section{Severity Scale}

The scores of the 19 SLTs were consistent with the expert group for $53.2 \%$. The correlation of dysarthria severity with both the SHI $\left(r_{s}=0.40, p<0.01\right)$ and the NSVO$\mathrm{Z}\left(r_{\mathrm{s}}=-0.65, p<0.01\right)$ was substantial, whereas the correlation of dysarthria severity with the category fluency task was weak $\left(r_{s}=-0.28, p=0.05\right)$ (Table 4$)$. The interrater and intra-rater reliability of the severity scale was high (ICCs 0.85 or 0.86 ).

Table 3. The factor loadings of the different items of the rating sheet on the four components

\begin{tabular}{|c|c|c|c|c|}
\hline \multirow[t]{2}{*}{ Items } & \multicolumn{4}{|c|}{ Component } \\
\hline & 1 & 2 & 3 & 4 \\
\hline Lip movements & 0.55 & 0.60 & & \\
\hline Jaw movements & 0.51 & 0.43 & & \\
\hline Tongue movements & & 0.65 & & \\
\hline Vowels & & 0.73 & & \\
\hline Consonants & & 0.80 & & \\
\hline Clusters & & 0.81 & & \\
\hline Syllable structure & & 0.79 & & \\
\hline Oral diadochokinetics & & 0.72 & & \\
\hline Resonance & & & & 0.83 \\
\hline Vocal quality & 0.82 & & & \\
\hline Vocal use & 0.79 & & & \\
\hline Loudness & 0.66 & & & \\
\hline Pitch & 0.70 & & & \\
\hline Fundamental frequency range & 0.82 & & & \\
\hline Maximum phonation volume & 0.64 & & & \\
\hline Maximum phonation duration & 0.57 & & 0.55 & \\
\hline Inhalation & & & 0.59 & \\
\hline Breathing pattern & 0.41 & & 0.75 & \\
\hline Breath groups & 0.44 & & 0.68 & \\
\hline Melodic accent & 0.52 & & 0.53 & \\
\hline Dynamic accent & 0.53 & & 0.64 & \\
\hline Temporal accent & & & 0.67 & \\
\hline Cronbach's a & 0.89 & 0.90 & 0.91 & \\
\hline
\end{tabular}

Factor loadings suppressed below 0.4. Bold numbers indicate the highest factor loading per item.

\section{Self-Evaluation Questionnaire}

The internal consistency of the self-evaluation questionnaire was high (Cronbach's $\alpha=0.90$ ).

The correlation of the self-evaluation questionnaire with the SHI was strong $\left(r_{\mathrm{s}}=0.80, p<0.01\right)$, with the NSVO-Z substantial $\left(r_{\mathrm{s}}=-0.52, p<0.01\right)$, and with category fluency weak $\left(r_{\mathrm{s}}=-0.27, p=0.06\right)$ (Table 4$)$.

\section{Discussion}

In this paper, we present the RDA, a standardised set of common speech and maximum performance (speechlike) tasks for the perceptual analysis of speech, using a qualitative recording form, a severity scale and a self-evaluation questionnaire. We established its clinimetric properties in adult Dutch-speaking persons, but the RDA itself is not language-specific and easy to construct in any other language.

Factor analysis indicated that the items on the recording form represent 4 domains of speech production: phonation, articulation, respiration/prosody, and resonance. We had expected that prosody would be identified as a separate dimension, but our results demonstrated that it proved to be part of the respiration domain. This is conceivable as it is a supra-segmental aspect of speech. Because the internal consistency within each dimension was good, it is safe to conclude that the items within each domain were adequate.

The severity scale showed good intra- and inter-rater reliability scores, indicating that it is sufficiently accurate to be used in clinical practice by SLTs. Regarding the validity, the fact that the correlation between dysarthria severity (which is clinician rated) and the SHI (which is patient rated) was substantial $\left(r_{s} \geq 0.40\right)$ but not strong $\left(r_{s}\right.$ $\geq 0.70$ ) is plausible. Whether patients experience problems due to dysarthria as indicated by the SHI is highly personal and depends on their daily activities. This emphasises that collecting clinician-rated scores as well as

Table 4. The Spearman's correlation coefficients ( $p$ value) between the severity of dysarthria, the self-evaluation questionnaire, the Speech Handicap Index (SHI) [28], intelligibility (NSVO-Z) [11] and the category fluency task in the 43 patients

\begin{tabular}{lllll}
\hline & Dysarthria severity & SHI & NSVO-Z & Fluency \\
\hline Dysarthria severity & 1.00 (n.a.) & $0.40(p<0.01)$ & $-0.65(p<0.01)$ & $-0.28(p=0.05)$ \\
Self-evaluation questionnaire & $0.53(p<0.01)$ & $0.80(p<0.01)$ & $-0.52(p<0.01)$ & $-0.27(p=0.06)$ \\
\hline
\end{tabular}

n.a., not applicable. 
patient reports is important for setting shared treatment goals [32]. The substantial $\left(r_{\mathrm{s}}=-0.65\right)$ (but not strong) correlation between dysarthria severity and the NSVO-Z is conceivable as well. Patients with severe dysarthria according to the RDA can still be intelligible according to the NSVO-Z, if they adapt their speaking technique [3]. In line with our hypothesis, dysarthria severity correlated only weakly with category fluency, because the latter is dependent on linguistic ability rather than speech capacity. Overall, the results support the construct validity and reliability of the severity scale.

The self-evaluation questionnaire showed good internal consistency, indicating that all questions measure the same construct. The strong correlation between the selfevaluation questionnaire and the SHI indicates that SLTs can choose either questionnaire to obtain information about the speech difficulties as perceived by the patient. The weak to substantial correlations with category fluency and the NSVO-Z further underline that the selfevaluation questionnaire measures a specific and patientrated construct.

The improved RDA was based on national consensus and was, therefore, readily accepted as the preferred dysarthria assessment in the Netherlands according to sales figures and feedback during our postgraduate dysarthria courses. By striving to achieve consensus about the tasks, the terminology of the recording form, and the speech characteristics of the 43 patients, we learned at least two important lessons. We needed all tasks, including the maximum performance tasks, to reach consensus, in particular to distinguish primary deficits from compensatory mechanisms that patients used to optimise their speech. At the same time, we did not anticipate that reaching consensus with highly experienced clinicians would be such a time-consuming challenge. It seems that experienced clinicians all have their own internal acoustic anchors, which makes it even more important that we managed to reach consensus for the use of our instrument in the Netherlands and Flanders.

We primarily aimed at publishing a concise perceptual clinical assessment to be used by any dedicated SLT in daily practice. Nevertheless, by adding normative values for the maximum performance tasks [24] and a reading text adapted for acoustic measurements, the RDA is also suitable for scientific purposes, for instance for the objective registration and analysis of speech tasks. During our study, there was hardly any dysarthria assessment that we could use as a reference. Recently, the German instrument Bogenhausen Dysarthria Scales (BoDys) has been published [33], which is also a fully perceptual as- sessment, but with 4 tasks to elicit connected speech only (conversational speech, sentence repetition, text reading, and picture story). Because this instrument is based on a different theoretical approach that strictly distinguishes speech motor control from the motor control of speechlike tasks [14], a direct comparison between the RDA and BoDys is not possible.

\section{Future Perspectives}

The RDA has been developed for assessing adult neurological patients, but a paediatric version is underway with speech tasks adapted to children aged from 4 to 18 years, including age-related reference values for the maximum performance tasks. Because the RDA includes internationally accepted speech tasks and terminology, the instrument can easily be translated into other languages, with two possible limitations: every language may need its own set of videos with all dysarthria types and severities, and only future data gathering can demonstrate whether or not the reference values of the speech tasks are language dependent [34].

\section{Acknowledgements}

The authors would like to thank all patients and SLTs for their participation. In particular, Harry Goos, Judith Kocken, Lotte Kromhout, Marjo van Gerven, and Puck Goossens are acknowledged for providing their expertise during the development of the RDA. We thank Prof. Dr. A. Rietveld and Roos Haasnoot for their participation in the adaptation of the reading text and Dr. J.C.M. Hendriks for his statistical support.

\section{Disclosure Statement}

There are no conflicts of interest. 
Radboud Dysarthria Assessment (RDA)

\begin{tabular}{ll|}
\hline Name patient: & Date: \\
Date of birth: & SLT: \\
& \\
& \\
\hline
\end{tabular}

$0=$ normal $1=$ minimal problems $2=$ mild $/$ clear problems $\quad 3=$ severe problems $/$ impossible

\begin{tabular}{|c|c|c|c|c|c|}
\hline \multicolumn{6}{|c|}{ Articulation (spontaneous speech, reading, maximum repetition rate) } \\
\hline Lip movements: & $0-1-2-3$ & $\begin{array}{l}\text { O small } \\
\text { O slow } \\
\text { O asymmet }\end{array}$ & \multicolumn{2}{|c|}{$\begin{array}{l}\text { O tense } \\
\text { O flaccid } \\
\text { disadvantage to left / right }\end{array}$} & $\begin{array}{l}\text { O uncontrolled } \\
\text { O involuntary move- } \\
\text { ments }\end{array}$ \\
\hline Jaw movements : & $0-1-2-3$ & $\begin{array}{l}\text { O small } \\
\text { O slow }\end{array}$ & \multicolumn{2}{|l|}{$\begin{array}{l}\text { O tense } \\
\text { O flaccid }\end{array}$} & $\begin{array}{l}\text { O involuntary move- } \\
\text { ments }\end{array}$ \\
\hline Tongue movements: & $0-1-2-3$ & $\begin{array}{l}\text { O small } \\
\text { O slow } \\
\text { O asymmet }\end{array}$ & \multicolumn{2}{|c|}{$\begin{array}{l}\text { O tense } \\
\text { O flaccid } \\
\text { disadvantage to left / right }\end{array}$} & $\begin{array}{l}\text { O uncontrolled } \\
\text { O involuntary move- } \\
\text { ments }\end{array}$ \\
\hline Vowels: & $0-1-2-3$ & O distorted & O prolonged & \multicolumn{2}{|l|}{ O shortened } \\
\hline Consonants: & $0-1-2-3$ & O flaccid & O tense & O imprecise & O prolonged \\
\hline Clusters: & $0-1-2-3$ & \multicolumn{2}{|c|}{ O schwa- insertion } & O reduced & O imprecise \\
\hline Syllable structure: & $0-1-2-3$ & \multicolumn{2}{|c|}{ O phoneme-/syllable repetitions } & \multicolumn{2}{|c|}{ O phoneme-/syllable omissions } \\
\hline \multicolumn{6}{|c|}{ 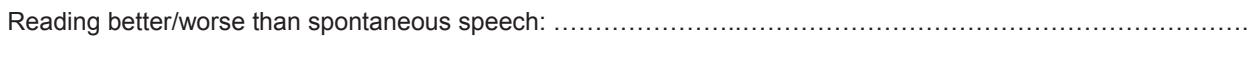 } \\
\hline \multicolumn{6}{|c|}{ 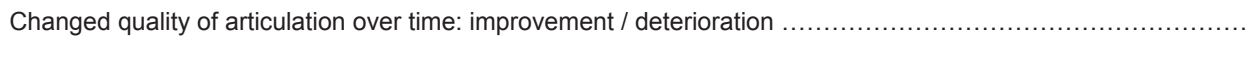 } \\
\hline \multirow{4}{*}{$\begin{array}{l}\text { Maximum } \\
\text { repetition rate }\end{array}$} & $0-1-2-3$ & $\begin{array}{l}\text { O flaccid } \\
\text { O tense }\end{array}$ & $\begin{array}{l}\text { O slow } \\
\text { O dysrhythmic }\end{array}$ & \multicolumn{2}{|c|}{ O problems increase } \\
\hline & $0-1-2-3$ & $\begin{array}{l}\text { O flaccid } \\
\text { O tense }\end{array}$ & $\begin{array}{l}\text { O slow } \\
\text { O dysrhythmic }\end{array}$ & \multicolumn{2}{|c|}{ O problems increase } \\
\hline & $0-1-2-3$ & $\begin{array}{l}\text { O flaccid } \\
\text { O tense }\end{array}$ & $\begin{array}{l}\text { O slow } \\
\text { O dysrhythmic }\end{array}$ & \multicolumn{2}{|c|}{ O problems increase } \\
\hline & $0-1-2-3$ & $\begin{array}{l}\text { O flaccid } \\
\text { O tense }\end{array}$ & $\begin{array}{l}\text { S slow } \\
\text { O dysrhythmic }\end{array}$ & \multicolumn{2}{|c|}{$\begin{array}{l}\text { O disturbed pattern } \\
\text { O problems increase }\end{array}$} \\
\hline
\end{tabular}

Resonance (spontaneous speech, reading)

Nasality: $\quad 0-1-2-3 \quad$ O hyper $\quad$ O hypo $\quad$ variable $\quad$ nasal emission

Reading better/worse than spontaneous speech: .....

Changed quality of nasal resonance over time: improvement / deterioration.

Observations

Phonation (spontaneous speech, reading, fundamental frequency range, maximum phonation volume, maximum phonation duration)

\begin{tabular}{|c|c|c|c|c|c|}
\hline Vocal quality: & $0-1-2-3$ & $\begin{array}{l}\text { O breathy } \\
\text { O tremor } \\
\text { O cracking }\end{array}$ & $\begin{array}{l}\text { O harsh } \\
\text { O staccato }\end{array}$ & $\begin{array}{l}\text { O diplophonic } \\
\text { O falsetto }\end{array}$ & $\begin{array}{l}\text { O aphonic } \\
\text { O unsteady }\end{array}$ \\
\hline Vocal use: & $0-1-2-3$ & O hypotonic & O hypertonic & & \\
\hline Loudness: & $0-1-2-3$ & O increased & $\mathrm{O}$ reduced & O uncontrolled & \\
\hline Pitch: & $0-1-2-3$ & O high & O low & O uncontrolled & \\
\hline
\end{tabular}




\section{Radboud Dysarthria Assessment (RDA)}

\begin{tabular}{|c|c|c|}
\hline Fundamental freq range: $0-1-2-3$ & $\mathrm{O}$ reduced & trolled \\
\hline Max phonation volume: 0 - $1-2$ - 3 & O reduced & O strained \\
\hline Max phonation time: & $\begin{array}{l}\text { O impaired quality } \ldots \ldots \ldots \ldots \ldots \ldots \\
\text { s/z ratio: } \ldots \ldots \ldots \ldots \ldots \ldots \ldots \ldots \ldots \ldots\end{array}$ & O deviant duration: $\ldots \ldots \ldots \ldots$ sec. \\
\hline
\end{tabular}

Respiration (during speech) (spontaneous speech, reading, maximum phonation volume, maximum phonation duration)

Place

O clavicular

O costal

O costo-abdominal

O abdominal

Inhalation:

$0-1-2-3$

O irregular

O stridor without phonation

O stridor with phonation

Respiration

$$
0-1-2-3
$$

O short breath groups

O short breath support

O impaired coordination

during speech:

$0-1-2-3$

O forced

O shallow

O paradoxical

of breathing:

Reading better/worse than spontaneous speech:

Observations:

\begin{tabular}{|c|c|c|c|}
\hline \multicolumn{4}{|c|}{ Prosody (spontaneous speech, reading) } \\
\hline Melodic accent: 0 - 1 - 2 - 3 & O monopitch & O unnatural & O uncontrolled / excess \\
\hline Dynamic accent: 0 - 1 - 2 - 3 & \multicolumn{2}{|c|}{ O monoloudness } & O uncontrolled / excess \\
\hline Temporal accent: 0 - 1 - 2 - 3 & $\begin{array}{l}\text { O slow } \\
\text { O chanted }\end{array}$ & $\begin{array}{l}\text { O accelerations } \\
\text { O stop problems }\end{array}$ & $\begin{array}{l}\text { O variable } \quad \text { fast } \\
\text { O start problems }\end{array}$ \\
\hline
\end{tabular}

Reading better/worse than spontaneous speech:

Observations

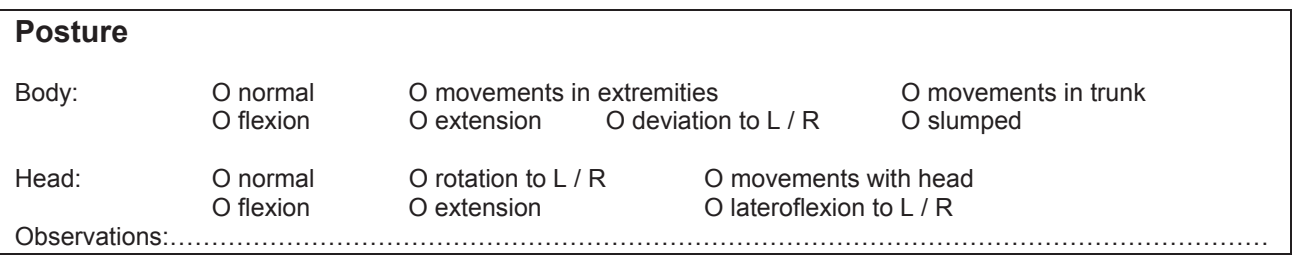

\section{Other}

O apraxia of speech $\quad$ O dental problems, nl.

O physical capability $\downarrow \quad$ O control of saliva $\downarrow$

O other.

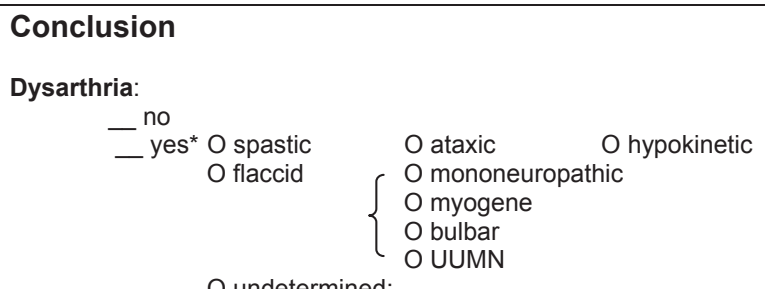

Conclusion

Dysarthria:

* in case of mixed dysarthrias, tick two or more types 


\title{
Radboud Dysarthria Assessment (RDA)
}

\author{
Severity scale: \\ 0 . No dysarthria \\ 1. Minimal dysarthria: minimal problems with articulation, resonance, phonation or respiration. \\ 2. Mild dysarthria: tonus, range of motion or speed of articulation movements are mildly affected, leading to mildly \\ affected consonants and/or vowels. Mild problems with resonance, phonation or respiration. \\ 3. Mild / severe dysarthria: tonus, range of motion or speed of articulation movements are clearly affected, leading \\ to deviant consonants and/or vowels. Clearly affected resonance, phonation or respiration. \\ 4. Severe dysarthria: tonus, range of motion or speed of articulation movements are severely affected, leading to \\ severely affected consonants and/or vowels. Severely affected resonance, phonation or respiration. Very slow \\ speech with only a few syllables per breath group. \\ 5. Very severe dysarthria/anarthria: articulation movements are almost impossible, leading to mainly open vowels \\ and very severely distorted consonants. Very severely affected resonance, phonation (aphonic) or respiration \\ (almost no breath support)
}

* in case of mixed dysarthrias, tick two or more types

\section{References}

1 Darley FL, Aronson AE, Brown JR: Differential diagnostic patterns of dysarthria. J Speech Hear Res 1969;12:246-269.

2 Darley FL, Aronson AE, Brown JR: Motor Speech Disorders. Philadelphia, Saunders Company, 1975.

3 Duffy JR: Motor Speech Disorders; Substrates, Differential Diagnosis and Management, ed 3. Missouri, Elsevier Mosby, 2013.

4 de Souza RF, Marra J, Pero AC, Compagnoni MA: Effect of denture fabrication and wear on closest speaking space and interocclusal distance during deglutition. J Prosthet Dent 2007; $97: 381-388$.

5 Howell P: Effect of speaking environment on speech production and perception. J Hum Environ Syst 2008;11:51-57.

6 Enderby P, Palmer R: FDA-2: Frenchay Dysarthria Assessment, ed 2. Austin, PRO-ED, 2008.

7 Lambert J, Rutten C: Frenchay Dysartrie Onderzoek. Lisse, Swets \& Zeitlinger, 1996.

8 Knuijt S, De Swart BJM: Handleiding Dysartrieonderzoek bij Volwassenen. Nijmegen, UMC St Radboud, 2007.

9 Kalf JG, de Swart B: Radboud Oraal Onderzoek 2007. www.radboudumc.nl.

10 de Bodt MS, Guns C, van Nuffelen G: Nederlands Spraakverstaanbaarheidsonderzoek. Antwerpen, Universitair Ziekenhuis Antwerpen, 2006.
11 Martens H, Van Nuffelen G, De Bodt M: Nederlands Spraakverstaanbaarheidsonderzoek Zinsniveau. Belsele, VVL, 2010.

12 Knuijt S: The Dutch Dysarthria Assessment, also a reliable instrument? 29th World Congr Int Assoc Logop Phoniatr (IALP), Turin, August 2013.

13 Knuijt S, Kalf JG: Assessment of dysarthria. 9th Eur Congr Comité Permanent de Liaison des Orthophonistes (CPLOL), Florence, May 2015.

14 Maas E: Speech and nonspeech: what are we talking about? Int J Speech Lang Pathol 2016; 19:345-359.

15 Staiger A, Schölderle T, Brendel B, Ziegler W: Dissociating oral motor capabilities: evidence from patients with movement disorders. Neuropsychologia 2017;95:40-53.

16 Ziegler W: Speech motor control is task-specific: evidence from dysarthria and apraxia of speech. Aphasiology 2003;17:3-36.

17 Ballard KJ, Robin DA, Folkins JW: An integrative model of speech motor control: a response to Ziegler. Aphasiology 2003;17:2748.

18 Kent RD, Kent JF, Rosenbek JC: Maximum performance tests of speech production. J Speech Hear Disord 1987;52:367-387.
19 Ackermann H, Hertrich I, Hehr T: Oral diadochokinesis in neurological dysarthrias. Folia Phoniatr Logop 1995;47:15-23.

20 Bomans G: Sprookjes. Amsterdam, Elsevier, 1973.

21 Rietveld ACM: Aandachtspunten bij de samenstelling van spraakmateriaal dat voor assessment- en effectstudies gebruikt kan worden. Nijmegen, Radboud University, 2011.

22 Rietveld ACM, Van Heuven VJ: Algemene Fonetiek, ed 3, revised. Bussum, Coutinho, 2009.

23 Boone DR: The Voice and Voice Therapy. Englewood Cliffs, Prentice-Hall, 1977.

24 Knuijt S, Kalf JG, Van Engelen BGM, Geurts $\mathrm{ACH}$, de Swart BJM: Reference values of maximum performance tests of speech production. Int J Speech Lang Pathol 2017;1-9.

25 Enderby P, John A: Therapy Outcome Measures: Speech-Language Pathology, ed 2. San Diego, Singular Publishing Group, 1997.

26 Kalf JG, Borm GF, de Swart BJ, Bloem BR, Zwarts MJ, Munneke M: Reproducibility and validity of patient-rated assessment of speech, swallowing, and saliva control in Parkinson's disease. Arch Phys Med Rehabil 2011;92: 1152-1158.

27 International Classification of Functioning, Disability and Health (ICF). Geneva, World Health Organisation, 2001. 
28 Van den Steen L, Van Nuffelen G, Guns C, De Groote M, Pinson L, De Bodt M: De spraak handicap index: een instrument voor zelfevaluatie bij dysartriepatiënten. Logopedie 2011; 24:26-32.

29 Diesfeldt HFA, Van der Elst W, Jolles J: Klinische bruikbaarheid van categoriegebonden woordproductie voor het onderscheiden van dementie en normale cognitieve veroudering. Tijdschr Gerontol Geriatr 2009;40:5471.
30 Aday LA: Designing and Conducting Health Surveys. San Francisco, Jossey-Bass, 1996.

31 Terwee CB, Bot SD, de Boer MR, van der Windt DA, Knol DL, Dekker J, et al: Quality criteria were proposed for measurement properties of health status questionnaires. J Clin Epidemiol 2007;60:34-42.

32 Hartelius L, Elmberg M, Holm R, Lovberg AS, Nikolaidis S: Living with dysarthria: evaluation of a self-report questionnaire. Folia Phoniatr Logop 2008;60:11-19.
33 Ziegler W, Staiger A, Schölderle T, Vogel M: Gauging the auditory dimensions of dysarthric impairment: reliability and construct validity of the Bogenhausen Dysarthria Scales (BoDyS). J Speech Lang Hear Res 2017;60: 1516-1534.

34 Icht M, Ben-David BM: Oral-diadochokinesis rates across languages: English and Hebrew norms. J Commun Disord 2014;48:27-37. 